\title{
Factors influencing trust of teachers among students
}

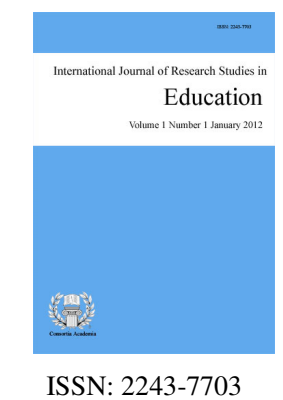

Kurnianingsih, Sri

Center for Indigenous \& Cultural Psychology, Faculty of Psychology, Universitas Gadjah Mada, Yogyakarta, Indonesia (skurnianingsih2004@yahoo.com)

Yuniarti, Kwartarini Wahyu $\triangle$

Center for Indigenous \& Cultural Psychology, Faculty of Psychology, Universitas Gadjah Mada, Yogyakarta, Indonesia (kwartarini_yuniarti@yahoo.com)

Kim, Uichol

College of Business Administration, Inha University, Incheon, Korea (uicholk@yahoo.com)

OPEN ACCESS

Received: 10 November $2011 \quad$ Revised: 22 December $2012 \quad$ Accepted: 24 January 2012 Available Online: 25 January 2012 DOI: $10.5861 /$ ijrse.2012.v1i2.77

\section{Abstract}

In Indonesia, Ki Hajar Dewantoro is one of the most respected scholars in education philosophy. He stated the importance of trust earned by teachers in guiding students in their learning activities. The teacher, as the leader in the class, needs to develop mutual trust between students and teachers. Trust to teachers is strongly required by students as a foundation in developing and expanding their relationship and also social network. It is also the fundamental element in their desire to pursue higher education, for it is only through a sense of trust that student will embrace an empowering sense of freedom and pursuit the knowledge. The exercise of this freedom requires a risk on behalf of students based on the trust of their teachers and the learning experience that they provide. If students trust their teachers, they will be more able to focus on the task at hand and to work and learn more effectively. A total number of 291 senior high school students in Yogyakarta (males=147, females=144) completed an open-ended questionnaire developed for this study that asks how much they trust their teachers and the reason why they trust their teachers. The data was analyzed using indigenous psychological approach of analyzing the content of open-ended responses, categorization of the responses and cross-tabulating with demographic/background information. Results indicated that $63 \%$ of participants stated that they trusted their teachers. The main reason for trusting their teachers are as follows: they are perceived as being similar to their parents, teachers' ability in transferring knowledge, the relationship with teacher, and their abilities of guiding students. The study concluded that trust of senior high school students was established because of views that teachers are parents that have competence in delivering knowledge and are formally established as teachers. Therefore a teacher's behavior that similarly represents a parent's behavior at home will produce a child's trust and this will become the foundation for the students to learn better.

Keywords: trust; high school students; indigenous psychology; achievement; teachers 


\section{Factors influencing trust of teachers among students}

\section{Introduction}

One of the major problems in Indonesia, particularly concerning education, is the quality of teachers (Suryadarma et al., 2006). The quality of learning processes within the class largely relies on the quality of teachers and the interaction of these two elements will eventually influence the quality of the students, as outputs of the learning process. It is hoped that within the classroom atmosphere, teachers play the role as agents of change, where teachers are able to provide stimulus necessary for the students' cognitive, affective and psychomotor growth.

The above elaboration is in agreement with the philosophy addressed by Ki Hajar Dewantara (1935), suggesting that teachers are leaders that manage the cognitive (cipta), affective (rasa), and psychomotor (karsa) development of their students. Capabilities of the teachers to fulfill this particular role strongly determine both academic and non academic outcomes of the students. One particular non-academic outcome necessary to be developed by teachers is the growth of trust within students themselves as well as trust towards other students. Of course, this requires the teachers to become trustworthy figures themselves. Failure to fulfill this role, would lead to distrust to the teachers and as a consequence, processes of establishing student trust would not be achieved. Unfortunately, several facts reveal that teachers abandon the trust granted to them. Several cases in the mass media demonstrated relatively severe cases including assault to students, deception or other legal violations, as well as common cases of poor teaching competence in managing the students in class. As a result the students' trust diminishes or eliminates all together. Low level of trust will eventually lead to difficulties for students to absorb the lessons delivered by the teachers. Hence, the current study aimed to investigate factors that influencing trust to teachers among adolescents with the teachers' roles as leaders in forming trust from their students. This is particularly in recognition of how teachers are an extension of trust from the students' parents, of which was established earlier within relations at home.

\subsection{Research Questions}

The trust explored in this study refers to trust to teachers as one of the components from the teacher's roles as a leader in the class. The following question constitutes the research question in the study: What factors influence trust to teachers?

\section{Literature review}

\subsection{Studies on trust}

The term trust is defined by both historical and socio-cultural antecedents, and therefore results in several different meanings. However, within the same cultural context, consensus is more likely to be achieved when referring to the equivalent meanings of what and whom to trust (Kim \& Choi, 2002). Moreover, Kim and Choi (2002) suggested that the alternative to overcome the diverse interpretations due to the lack of agreement and clarification, is to clarify its meaning through an indigenous perspective, primarily concerning how people use and analyze the concept of trust. It becomes essential to study how trust is used in daily life as well as the contexts that they are used. Indigenous studies concerning trust carried out by Kim \& Choi (2002) in East Asia demonstrate that trust is a relational concept as opposed to an individual one. This concept provides security, harmony, and welfare to individuals and the community at large. The definition contrasts with Hardin's (2001) definition that suggests that trust is individually based and functions to fulfill interests that have an individualist orientation. This concept is based on the "prisoner's dilemma" model focusing on individuals within a situation 
Factors influencing trust of teachers among students

when the personal interests conflict with the interests of others (Yamagishi, 1999). This difference is caused by the cultural backgrounds and philosophies. Western culture emphasizes on rationale, thoughts, and inner self, evident from the quotes of philosophers as such Socrates, Shakespeare, and Descartes with self epistemology as the core of 'self'. Meanwhile in East Asia, such as Korea and China, in accordance with their Confucians philosophies, suggest that a person becomes him/herself not because of what occurs within one self but what occurs between humans (Kim, 2001).

Based on the Confucius approach, trust that based on morals and relations is the most important element in managing people and the society. However, colonialism or the emergence of dictatorship in the 20th century shifted the communities' focus in East Asia to merely create harmony within the family and thus lacked the significant interest and effort to establish a harmonious society (Kim \& Choi, 2002). Kim (2001) suggests that influences of modernization from traditional agricultural societies to become industrial countries causes cultural shifts, however the core value interpersonal closeness remains strong. In relation with the influence of modern progress, Yamagishi (1999) suggests that collective societies produce feelings of security but in turn undermine the trust they have already possessed. This is somewhat ironic considering that trust plays a very important role in transforming collective societies to open societies. In Igarasi et al. (2008), Yamagishi referred to trust as a person's belief towards a person's fine intentions to never bring harm to others, respect a person's rights, and fulfill obligations. Trust encourages cooperation (Rotter, 1971) and becomes a psychological lubricant in facilitating social processes (Igarashi et al., 2008). This statement confirms the suggestions from sociologists of the important role of trust plays in social network processes such as information channels, establishment of social norms, establishment of authorities as well as application of sanctions towards anti-normative behaviors (Coleman, 1988; Burt, 1993; Lin, 1999; Putnam, 2000).

Igarashi, Kashima, Farsides, Kim, Strack, Werth and Yuki (2008) all state that trust constitutes the principle in social life however not much is known of the role of trust in social network processes. Studies by Igarashi et al. (2008) investigated trust between generalized trust (basically people can be trusted) and relationism (people can be trusted when they have relations), as well as the characteristics of social networks in homogenous networks (extent of a person's access to friends that share similar attitudes) and closeness with networks (extent of closeness with social networks). A study was conducted in three Western countries (Australia, Germany, and England) along with two East Asian countries (Japan and Korea). The studies demonstrate that within all five countries, the research subjects view that generalized trust had positive associations with closeness of social networks while generalized trust and relationism had different associations with network homogeneity over different cultures.

The studies above are based on the classification of two types of trust elaborated by Yamagishi (1998) referring to generalized trust and assurance. Generalized trust is the general belief of a person's benevolence, that a person is trustworthy although exceptions remain. On the other hand, assurance refers to trust originating from relationships with others that feel secured because of the assurance that the person shall never betray the trust. Yamagishi also describes assurance trust with the metaphors of a person with thousands of needles inside his/her throat and whenever violation is evident, those needles would pierce that person. Therefore it is expected that the person never lies. The act of not lying itself, in any way reflects a person's noble character or emotional closeness, however, it is rather on his/her self intention. When we trust other people, it is assumed that they have control upon themselves, or are able to act in line with their desires, and are responsible of their own actions (Kim \& Choi, 2002). Although exceptions remain for those incapable of controlling themselves (for example children and people with special needs) of which are assumed that their behaviors represent manifestation that emerge from the deepest intentions, agency and behaviors that are used to prove the intentions of a person. Therefore the concept of trust also encompasses intentions to act, of which is controlled within actions, as well as future actions that will be taken account for.

In relation to the trusted party, individuals originating from Scandinavia have stronger trust to colleagues beyond their group compared to individuals from East Asia (Kim \& Park, 2005). These differences are evident in 
applications of democracy and human rights. Furthermore, it was discovered that individuals in East Asia have stronger trust towards government institutions and politicians. Therefore in Scandinavia, leaders are chosen for their ideas, whereas in Korea, leaders are chosen because of paternalistic relations and morals. Meanwhile in Japan, paternalistic leaders are not favored much.

\subsection{Trust to teacher as a leader in classroom}

Trust developed ever since the natal years of a child, through relations between students and parents. Basic trust grows when the recipient feels consistent, predictable, and reliable nurturing pattern (Crain, 2000). On the other hand, mistrust will emerge when those conditions of nurturance are not met. Choi and Kim (2002) suggest that trust develops from a child in line with the child's growth. Within the initial stages, the child develops strong degree of trust with their parents. In the next process, the child's trust develops to the family. School is viewed as an extension of the family. Personal relations with the child and parents are extended to the teachers who are viewed as parents and friends, and they are treated as the extension of family members. Berns (2007) stated that the school acts as the societies' agent in transferring knowledge, skills, customs, and beliefs in the society. Teachers were also once thought of as moral authorities who upheld cultural standards and societal norms (Durkheim, 1956). The strongest influence of socialization in school relies on the parties that interpret the goals of programs into actions, and in this case teacher (Brophy, 1992).

Teachers also play a significant role in their leadership to facilitate the child to build relationships with dominant parties, work together with others, and acquire competence (Berns, 2007). Gregory and Ripski (2008) in their study on "students trust to teacher" have found out that teachers may earn the trust and cooperation of students if they use relationship building to prevent discipline problems. While Lee (2007) revealed that the trust relationship between student and teacher played an important role as a key predictor of adolescents' school adjustment, academic motivation and performance. Demands so that teachers acquire roles as leaders to the children in aspects of forming behavior, providing guidance, and supervising were also expressed by Ki Hajar Dewantara (1935). Processes of establishing trust will expand in line with the development of social relationship within his/her environment.

Development of trust in a broader scope to strangers and to foreign people (different ethnicity), along with the extent of a person's ability in building relationships with others depends on the types and levels of trust followed by the person. Yamagishi (1986) mentioned two types of trust, namely generalized and particularistic, of which serve different functions of its establishment and management in social networks. Generalized trust encourages a person to approach other people in establishing social networks. People with higher levels of generalized trust are likely to work together with other people compared with lower degrees of trust. In contrast, particularistic trust is largely defined by emotional closeness that facilitates management of social relationships. Emotional closeness becomes a foundation in building relationships and may potentially become a barrier in the process of developing new social relationships (Igarashi et al., 2008).

Trust is referred to as the level of trust acquired by a person upon the competence and willingness of others to act fairly, ethically, and predictably (Nythan \& Marlowe, 1997). A number of dimensions of trust are discovered (Cufaude, 1999; Maren et al., 1999; Sparks, 2000), including trust between leaders and followers (Barling et al., 2003; Cherry, 2000; Costigan et al., 1998; Dirks \& Ferrin, 2002; Korsgaard et al., 2002; Velez, 2000), and trust within organizations (Armstrong-Stassen et al., 2001; Courtney, 1998; Daley \& Vasu, 1998; Gilbert \& Tang, 1998; Shockley-Zalabak et al., 2000).

Leaders produce and bridge trust (Bennis, 2002; DePree, 2002) through their behaviors. Communicative and supportive behaviors become primary determinants of trust to leaders (Gimbel, 2001; Tschannen-Moran \& Hoy, 1998). Simons (1999) theorized that behaviors of integrity, referring to the levels of perception upon the consonance between upheld and practiced values, become important in developing a student's trust towards leaders. This theory is confirmed by Spark (2000) who stated that behaviors become a media for judgment and 
Factors influencing trust of teachers among students

action upon the perception of the overall trust towards a leader. Betrayal of trust will reduce levels of trust to the followers and may further lead to poor levels of contribution to the organization (Braun, 1997) particularly when leaders are put on blame as the cause of negative consequences (Korsgaard et al, 2002). The establishment of trust is strongly determined by the leader's ability to conduct social exchange through communication abilities towards the followers, whether from aspects of information (Shockley-Zalabak, 2001) or frequency of communication (Cheery, 2000; Kollock, 1994). In the dual-trust approach proposed by Meyer et al. (1995) within the organizational context, trust is viewed by the trustor as a function of ability, benevolence, and integrity in seeing the tendencies of trust to the trustee.

\section{Methods}

\subsection{Study participants}

The study participants consist of 291 senior high school students studying in Yogyakarta aged 15 - 18 years. They are 147 male and 144 female students, with three students not filling in the section of gender.

\subsection{Measures}

The measures used in this research was open-ended questionnaire of which was developed in a trust-questionnaires used at the indigenous psychology survey, carried out by the Center for Indigenous \& Cultural Psychology (CICP) at the Faculty of Psychology, Universitas Gadjah Mada.

\subsection{Data collection and analysis}

This study used an indigenous approach. Subjects of this study were 291 high school students. They answered question related to the reason they trust their teachers. The answers were subsequently categorized in accordance with the themes that emerged among the responses. Categorization was conducted by a group consisted of three doctoral students at the Faculty of Psychology Universitas Gadjah Mada to ensure the precision and the accuracy in establishing the themes. During the categorization process, information is sorted to a number of themes. Themes in this context, refers to ideas and topics that are detected within the analyzed material, and emerge more than once in the data set. The same theme may be described by different words, emerge in a different context, or is expressed by a different person. Therefore it requires great meticulousness by the researchers to identify the emerging themes. The step of the categorization were (a) preparing the data to be analyzed by compiling the data; (b) identifying specific item information that seem relevant with the topic being studied; (c) sort the data based on proto-themes; (d) test the proto-themes and formulate an initial definition (e) pay attention to each theme separately and carefully retesting each transcript for materials that are relevant to the themes; (f) use all material related to each theme to construct a final theme that contains a name, definition along with supporting data; and $(\mathrm{g})$ selecting data relevant to be made as an illustration in reporting each theme. Results of the categorization were further analyzed using cross tabulation with the respondents backgrounds.

\section{Results}

Based on the statistical analysis on 291 responses; 8.2\% respondents (24 students) answer that they trust their teachers "very much", 55.30\% (161 students) trust their teachers "much", $26.5 \%$ (77 students) "somewhat trust" their teachers, 9.6\% (28 students) have "little trust" and $0.3 \%$ (1 student) "did not trust his/her teacher at all". This results indicated that majority of students trust their teachers. Meanwhile, from 291 respondents there were 239 responses on open ended questionnaire of the students' reasons of why they trust their teachers that were analyzed. Those responses were categorized into 26 categories: as parents, meritorious service, role of teacher, role model, transferring knowledge, makes us clever, expert, competent, knowledgeable, scholar (high level of education), older, experience, honest, reliable, kind-hearted, responsible, helpful, character, understand me, trust me, closeness, giving guidance, will not led astray, demand for the best and give the best. Based on the 
content of each category, these categories were clustered into 9 major categories (themes) as seen in table 1.

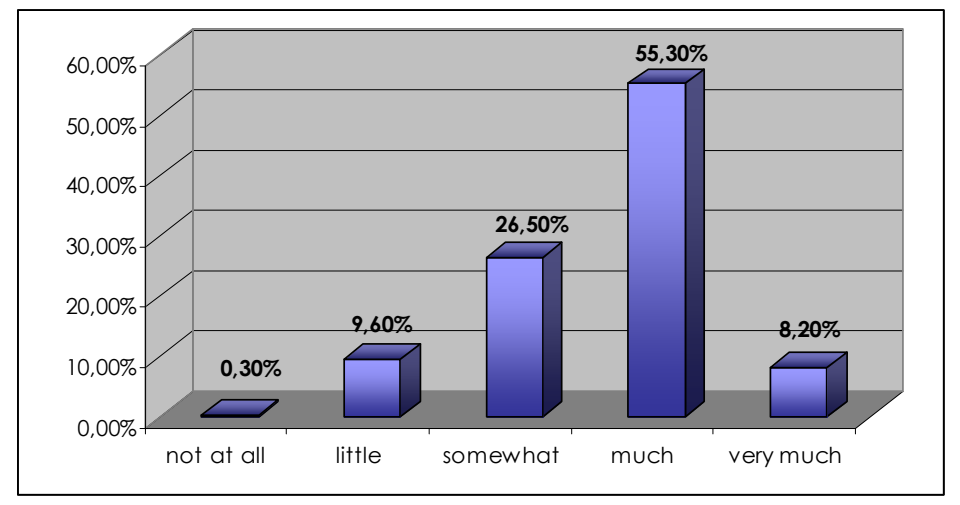

Figure 1. How much do you trust your teacher?

The categorical themes are as follows: teachers as parents in school (28\%), teachers give knowledge $(20.9 \%)$, roles as teachers $(14.2 \%)$, give guidance/direction $(12.5 \%)$, expertise/intelligence $(7.1 \%)$, character $(6.2 \%)$, gives support $(4.2 \%)$, meritorious service/work without expecting anything in return (4.2\%), and emotional relationship $(1.6 \%)$ as displayed in figure 2.

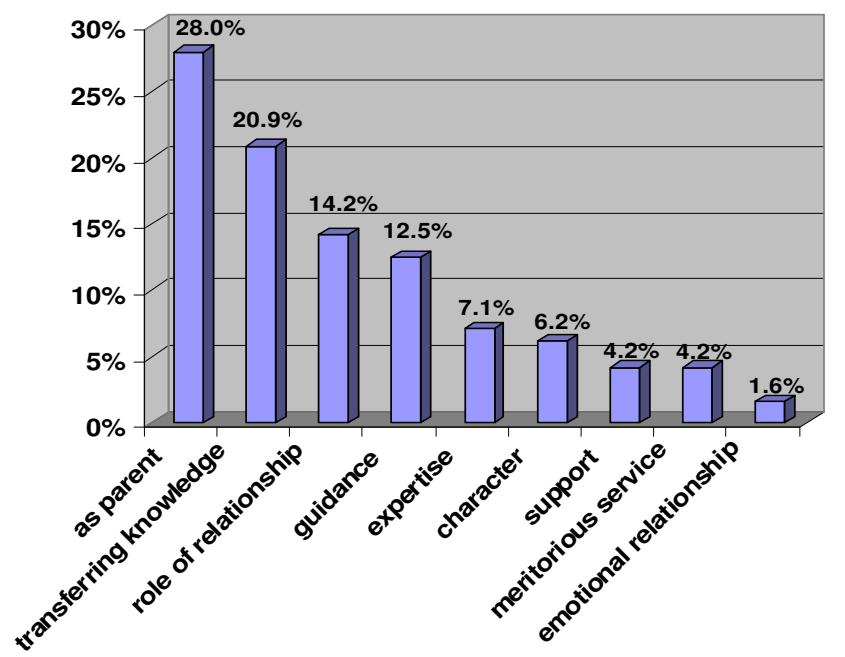

Figure 2. Themes on the reasons students' trust teachers

Major themes as displayed in the graphic are formed by a number of smaller thematic categories, except for the following themes: as parents (28\%) (first rank) and working without expecting anything in return/meritorious service $(4.2 \%)$ (seventh rank). Both of these major categories stand alone because of the large responses for the theme 'as parents' and the specific theme of meritorious service related to the Indonesian culture in perceiving teachers' task. In second rank contains the category of providing knowledge $(20.9 \%)$ that consists of the categories: providing knowledge $(20.5 \%)$ and make me clever $(0.4 \%)$. Ranking third is role/ task as teacher $(14.2 \%)$ consisting of the categorical themes role as a teacher $(12.1 \%)$ and role model $(2.1 \%)$. Ranked fourth is the category of guidance $(12.5 \%)$ consisting of giving direction $(11.7 \%)$ and will not lead astray $(0.8 \%)$. In the fifth rank, is the category expertise/intelligence $(7.1 \%)$ that consist of expertise/intelligence $(2.1 \%)$, competence $(2.1 \%)$, knowledgeable $(1.3 \%)$, educated $(0.8 \%)$, older $(0.4 \%)$, and experience $(0.4 \%)$. The following category is character $(6.2 \%)$ which is in the sixth rank, consisting of honest $(2.9 \%)$, reliable $(1.3 \%)$, kind $(0.8 \%)$, responsible $(0.4 \%)$, likes to help $(0.4 \%)$, character $(0.4 \%)$. The eighth category is emotional relationship (1.6\%) consisting of understands me $(0.8 \%)$, trusts me $(0.4 \%)$, and closeness $(0.4 \%)$. The last category or ninth ranked category is support (4.2\%) consisting of expecting the best (2.9\%) and giving the best (1.3\%).

Based on the correlation analyses between demographic variables and response categories in the major categorical themes, overall the variables did not indicate significant differences $(p>0.5)$. These demographic 
Factors influencing trust of teachers among students

variables include gender, location student was raised (village, city, large city), desired education level to achieve, religion, educational and occupational status of parents, living standards, and parent's occupation.

Table 1

Reasons for trusting teacher

\begin{tabular}{|c|c|c|c|c|c|c|}
\hline \multirow{2}{*}{ Categories } & \multirow{2}{*}{\multicolumn{2}{|c|}{ Total }} & \multicolumn{4}{|c|}{ Gender } \\
\hline & & & \multicolumn{2}{|c|}{ Male } & \multicolumn{2}{|c|}{ Female } \\
\hline 1. AS PARENTS & 67 & $28.0 \%$ & 35 & $14.6 \%$ & 31 & $13.0 \%$ \\
\hline 2. MERITORIOUS SERVICE & 10 & $4.2 \%$ & 6 & $2.5 \%$ & 3 & $1.3 \%$ \\
\hline 3. ROLE OF TEACHER & 34 & $14.2 \%$ & 17 & $7.2 \%$ & 17 & $7.1 \%$ \\
\hline - role of teacher & 29 & $12.1 \%$ & 14 & $5.9 \%$ & 15 & $6.3 \%$ \\
\hline - role model & 5 & $2.1 \%$ & 3 & $1.3 \%$ & 2 & $0.8 \%$ \\
\hline 4. TRANSFERRING KNOWLEDGE & 50 & $20.9 \%$ & 24 & $10 \%$ & 26 & $10.9 \%$ \\
\hline - transferring knowledge & 49 & $20.5 \%$ & 23 & $9.6 \%$ & 26 & $10.9 \%$ \\
\hline - make us clever & 1 & $0.4 \%$ & 1 & $0.4 \%$ & 0 & $0.0 \%$ \\
\hline 5. EXPERTISE & 17 & $7.1 \%$ & 10 & $4.2 \%$ & 7 & $2.8 \%$ \\
\hline - expert & 5 & $2.1 \%$ & 3 & $1.3 \%$ & 2 & $0.8 \%$ \\
\hline - competent & 5 & $2.1 \%$ & 4 & $1.7 \%$ & 1 & $0.4 \%$ \\
\hline - knowledgeable & 3 & $1.3 \%$ & 1 & $0.4 \%$ & 2 & $0.8 \%$ \\
\hline - scholar (high level of education) & 2 & $0.8 \%$ & 1 & $0.4 \%$ & 1 & $0.4 \%$ \\
\hline - older & 1 & $0.4 \%$ & 1 & $0.4 \%$ & 0 & $0.0 \%$ \\
\hline - experience & 1 & $0.4 \%$ & 0 & $0.0 \%$ & 1 & $0.4 \%$ \\
\hline 6. CHARACTER & 15 & $6.2 \%$ & 6 & $3.2 \%$ & 10 & $4.1 \%$ \\
\hline - honest & 7 & $2.9 \%$ & 2 & $0.8 \%$ & 5 & $2.1 \%$ \\
\hline - reliable & 3 & $1.3 \%$ & 2 & $0.8 \%$ & 1 & $0.4 \%$ \\
\hline - kind-hearted & 2 & $0.8 \%$ & 0 & $0.0 \%$ & 2 & $0.8 \%$ \\
\hline - responsible & 1 & $0.4 \%$ & 1 & $0.4 \%$ & 0 & $0.0 \%$ \\
\hline - helpful & 1 & $0.4 \%$ & 0 & $0.0 \%$ & 1 & $0.4 \%$ \\
\hline - character & 1 & $0.4 \%$ & 1 & $0.4 \%$ & 1 & $0.4 \%$ \\
\hline 7. EMOTIONAL RELATIONSHIP & 4 & $1.6 \%$ & 3 & $1,2 \%$ & 1 & $0.4 \%$ \\
\hline - understand me & 2 & $0.8 \%$ & 1 & $0.4 \%$ & 1 & $0.4 \%$ \\
\hline - trust me & 1 & $0.4 \%$ & 1 & $0.4 \%$ & 0 & $0.0 \%$ \\
\hline - closeness & 1 & $0.4 \%$ & 1 & $0.4 \%$ & 0 & $0.0 \%$ \\
\hline 8. GUIDANCE & 30 & $12.5 \%$ & 14 & $5.8 \%$ & 16 & $6.7 \%$ \\
\hline - giving guidance & 28 & $11.7 \%$ & 13 & $5.4 \%$ & 15 & $6.3 \%$ \\
\hline - won't let astray & 2 & $0.8 \%$ & 1 & $0.4 \%$ & 1 & $0.4 \%$ \\
\hline 9. SUPPORT & 10 & $4.2 \%$ & 4 & $1.7 \%$ & 6 & $2.5 \%$ \\
\hline - demand for the best & 7 & $2.9 \%$ & 3 & $1.3 \%$ & 4 & $1.7 \%$ \\
\hline - give the best & 3 & $1.3 \%$ & 1 & $0.4 \%$ & 2 & $0.8 \%$ \\
\hline
\end{tabular}

\section{Discussions}

Choi and Kim (2002) suggest that schools are extensions from the process of establishing a child's trust from the family. Personal relationships between the child and the parents are extended to the teachers who are viewed as parents and friends are treated as extensions of family members. This condition is portrayed in the study results that demonstrate the largest factor that allows students to trust their teachers is the view that teachers are substitutes to their parents in school. Some examples of the responses include: "because teachers are my second parents", "because teachers are our parents in school”, "Because teachers are my second parents after my parents at home, and although my second parents are in school however I still view them as my 
own parents", "Teachers are our parents in school that has always guided me". These responses demonstrate that a students' trust to teachers are related to assurance to trust formed by a relationship or emotional support and supportive (Igarashi, 2008), similar to student relationships with their parents.

Berns (2007) specifically mentions the characteristics of effective teachers including warmth, enthusiasm, often gives praises, able to communicate well and are responsive to the students. These characteristics are the characteristics that are possessed by parents when nurturing their children. Following categories include teachers providing guidance /direction, emotional relations as well as characteristics. Students perceive the teachers behavior that are similar with the parents' behavior at home. These things become the reasons that establish trust as similar with the childhood years when interacting with parents. This trust therefore becomes a basis for the child to make their parents as role models in the socialization learning process. Bandura (1989) stated that the model of imitation from children is perceived as warm, respect, able to control resources, and acquires the potential to strengthen behavior.

The aspects of the teacher's ability also become a reason why students trust their teachers. A number of the following responses were mentioned: "I trust the teachers and because teachers give us knowledge in school", "Because they have given me meaningful knowledge". "Because the teachers' intentions are solely to give knowledge to me and my friends". Teachers function to facilitate the students in achieving a particular competence (Berns, 2007). Furthermore it is also mentioned of the teacher's abilities to translate the aims of the programs into action (Brophy, 1992). Teachers are responsible to sort the lessons in accordance with the students, manage group dynamics within the class, and individually interact with each student.

Students trust teachers because of their roles or positions as teachers are ranked third. Not far from this category is that students view teachers to work without expecting anything in return or also referred to as heroes without labels of service (Indonesian idiom). Examples of this theme include: "Because teachers are educators and guides in the school", "Because they are heroes. They are the ones that give us knowledge and do not expect anything in return", "Because they are educators", "Teachers are people that serves us and they would never lie to their students". These reasons are formed by earlier conditioning from parents demanding that teachers should be trusted and followed/obeyed by the children. Within a Javanese context, the word 'guru' referring to teacher may serve as an abbreviation for 'digugu' (pay attention to) and 'ditiru' (followed/obeyed) reinforces the student's meaning towards teachers. The existence of such idioms "heroes without labels of honor" is also rooted within each student's mind and initially emerges every time a student is asked about their teachers.

\section{Conclusions}

Based on the findings above, it seems that trust of senior high school students is established because of views that teachers are parents that have competence in delivering knowledge and are formally established as teachers. Therefore a teacher's behavior that similarly represents parents' behavior at home will produce a child's trust and this will become the foundation for the students to learn better. Teachers are to be the child's role model in the child's ability to socialize in a broader environment from the family. The teacher's competence in teaching also becomes an important aspect for teachers to develop the students' trust towards them. These competences include mastery of class dynamics, mastery in teaching techniques, mastery of lesson material, as well as the ability to know the children well. This study implies that the significance expectation of the students towards their teachers needs to be conveyed to teachers strongly, so that the trust and the impact of education as results from a solid quality of interaction between teachers and students, having a strong foundation of trust, can be maintained and even improved.

\subsection{Limitations \& strengths of the study}

This study is by no means perfect. Since no random sampling employed in this, and consequently generalisation of the results is limited. Group discussions are further required to provide answers of some unclear 
Factors influencing trust of teachers among students

response from the questionnaire, this will enable the study seeing the dynamic of trust and its implication on the interaction between teachers and students. It is also limited to "students" focused study, which culturally limited to the group culture of students. Nevertheless, significant contribution of this study line up in the direction of originality and strong foundation of getting a more precise internal validity of the study and so people will be able to get the "right mirror" for themselves, and thefore providing a strong foundation for the future research agendas on the topic of interest, eg. Trust, students-teachers relationship, academic interaction etc.

Note: This article was presented in the 8th Biennial Conference of Asian Association of Social Psychology in New Delhi, India on December 2009.

\section{References:}

Armstrong-Stassen, M., Cameron, S. J., Mantler, J., \& Horsburgh, M. E. (2001). The impact of hospital amalgamation on the job attitudes of nurses. Revue Canadienne des Sciences de l'Administration, 18(3), 149-62.

Barling, J., Kelloway, E. K., \& Iverson, R. D. (2003). Accidental outcomes: Attitudinal consequences of workplace injuries. Journal of Occupational Health Psychology, 8(1), 74-85.

<http://dx.doi.org/10.1037/1076-8998.8.1.74>

Bennis, W. (2002). Become a tomorrow leader. In L. C. Spears (Ed.). Focus on leadership: Servant-leadership for the 21st century (pp. 101-109). New York, NY: Wiley.

Braun, C. (1997). Organizational infidelity: How violations of trust affect the employee-employer relationship.

The Academy of Management Executive, 11(4), 94-5. <http://dx.doi.org/10.5465/AME.1997.9712024843>

Brophy, J. E. (1992). Probing the subtleties of subject matter teaching. Educational Leadership, 49(7), 4-8.

Burt, R. S. (1993). Structural holes. Cambridge, MA: Harvard University Press.

Cherry, B. W. (2000). The antecedents of trust in a manager: The subordinate tells the story of time. Dissertation Abstracts International. UMI No. 9965903.

Coleman, J. (1988). Social capital in the creation of human capital. American Journal of Sociology, 94, 95-120. $<$ http://dx.doi.org/10.1086/228943>

Costigan, R. D., Ilter, S. S., \& Berman, J. J. (1998). A multi-dimensional study of trust in organizations. Journal of Managerial Issues, 10(3), 303-17.

Courtney, S. L. (1998). Impact of trust on employee perceptions of organizational and leader effectiveness.

Dissertation Abstracts International, UMI No. 9821684.

Crain, W. (2000). Theories of development: Concepts and applications. New Jersey: Prentice Hall.

Cufaude, J. (1999). Creating organizational trust. Association Management, 51(7), 26-35.

Daley, D. M., \& Vasu, M. L. (1998). Fostering organizational trust in North Carolina: The pivotal role of administrators and political leaders. Administration and Society, 30(1) 62-85. $<$ http://dx.doi.org/10.1177/009539979803000105>

DePree, M. (2002). Servant leadership: Three things necessary. In L. C. Spears (Ed.). Focus on leadership: Servant-leadership for the 21st century (pp. 89-97). New York, NY: Wiley.

Dewantara, K. H. (1935). Keluarga sebagai pusat pendidikan [Family as a center of education]. Warsita, May, $1(3)$.

Dirks, K. T., \& Ferrin, D. L. (2002). Trust in leadership: Meta-analytic findings and implications for research and practice. Journal of Applied Psychology, 87(4), 611-28.

$<$ http://dx.doi.org/10.1037/0021-9010.87.4.611>

Durkheim, E. (1956). Education and sociology. New York: Free Press.

Gilbert, J. A., \& Tang, T. L. (1998). An examination of organizational trust antecedents. Public Personnel Management, 27(3), 321-38.

Gimbel, P. A. (2001). Understanding principal trust-building behaviors: Evidence from three middle schools. Dissertation Abstracts International. UMI No. 3018320 
Kurnianingsih, S., Yuniarti, K. W., \& Kim, U.

Hardin, R. (2001). Gaming trust. In E. Ostrom \& J. Walker (Eds.) Trust and reciprocity: Interdisciplinary lessons from experimental research (Vol. VI, pp. 80-102). New York: Russell Sage Foundation.

Igarashi, T., Kashima, Y., Kashima, E. S, Farsides, T., Kim, U., Strack, F., Werth, L., \& Yuki, M. (2008) Culture, trust, and social networks. Asian Journal of Social Psychology, 11, 88-101. <http://dx.doi.org/10.1111/j.1467-839X.2007.00246.x>

Kim, U. (2001). Culture, science and indigenous psychologies: An integrated analysis. In D. Matsumoto (Ed.), Handbook of culture and psychology (pp. 51 -76). Oxford: Oxford University Press.

Kim, U., \& Choi, S. (2002). Emotional attachment as the basis of trust and interpersonal relationship: Psychological, indigenous, and cultural analysis. Yogjakarta: Tidak Diterbitkan.

Kim, U., \& Park, Y. (2005). Trust, relationship, and civil society in Scandinavia and East Asia: Psychological, social, and cultural analysis. Korean Journal of Psychological and Social Issues, 11, 133-161.

Kollock, P. (1994). The emergence of exchange structures: An experimental study of uncertainty commitment and trust. American Journal of Sociology, 100(2), 313-345. <http://dx.doi.org/10.1086/230539>

Korsgaard, M. A., Brodt, S. E., \& Whitener, E. M. (2002). Trust in the face of conflict: The role of managerial trustworthy behavior and organizational context. Journal of Applied Psychology, 87(2), 312-319. $<$ http://dx.doi.org/10.1037/0021-9010.87.2.312>

Lee, S. I. (2007). The relations between the student-teacher trust relationship and school. Educational Studies, 33(2), 209-216. <http://dx.doi.org/10.1080/03055690601068477>

Lin, N. (1999). Building a network theory of social capital. Connections, 22, 28-51.

Maren, R. S., Wicks, A. C., \& Huber, V. L. (1999). Cooperating with the disempowered using ESOPS to forge a stakeholder relationship by anchoring employee trust in workplace participation programs. Business and Society, 38(1), 51-83. <http://dx.doi.org/10.1177/000765039903800103>

Mayer, R. C., Davis, J. H., \& Schoorman, F. D. (1995). An integrative model of organizational trust. Academy of Management Review, 20, 709-734.

Nyhan, R. C., \& Marlowe, H. A. (1997). Development and psychometric properties of the organizational trust inventory. Evaluation Review, 21(5), 614-635. <http://dx.doi.org/10.1177/0193841X9702100505>

Putnam, R. D. (2000). Bowling alone: The collapse and revival of American community. New York: Simon \& Schuster.

Rotter, J. B. (1971). Generalized expectancies for interpersonal trust. American Psychologist, 26, 443-450. <http://dx.doi.org/10.1037/h0031464>

Shockley-Zalabak, P., Ellis, K., \& Winograd, G. (2000). Organizational trust: what it means, why it matters. Organization Development Journal, 18(4), 35-48.

Simons, T. L. (1999). Behavioral integrity as a critical ingredient for transformational leadership. Journal of Organizational Change Management, 12(2), 89-104. <http://dx.doi.org/10.1108/09534819910263640>

Sparks, J. (2000). Exploring trust: a dynamic and multidimensional model of interpersonal trust development in a task setting. Dissertation Abstracts International, UMI No. 3059879.

Suryadarma., D, Suryahadi., A, Sumarto., S, \& Rogers., F. H. (2006). Improving student performance in public primary schools in developing countries: Evidence from Indonesia. Education Economics, 14(4), 401-429. <http://dx.doi.org/10.1080/09645290600854110>

Tschannen-Moran, M., \& Hoy, W. (1998). Trust in schools: A conceptual and empirical analysis. Journal of Educational Administration, 36(4), 334-352. <http://dx.doi.org/10.1108/09578239810211518>

Velez, P. (2000). Interpersonal trust between supervisor and subordinate. Dissertation Abstracts International, UMI No. 3002301.

Yamagishi, T. (1986). The provision of a sanctioning system as a public good. Journal of Personality and Social Psychology, 51, 110-116. <http://dx.doi.org/10.1037/0022-3514.51.1.110>

Yamagishi, T., Cook, K. S., \& Watabe, M. (1998). Uncertainty, trust and commitment formation in the United States and Japan. American Journal of Sociology, 104, 165-194. <http://dx.doi.org/10.1086/210005>

Yamagishi, T., \& Kikuchi, M. (1999). Trust, gullibility, \& social intelligence. Asian Journal of Social Psychology, 2, 145-161. <http://dx.doi.org/10.1111/1467-839X.00030> 